\title{
Knitting Process Surveillance Using Time and Frequency Analysis
}

\author{
A. Catarino *, A. Rocha* , J.L. Monteiro** and F. Soares** \\ * University of Minho / Textile Engineering Department, Guimarães, Portugal \\ ${ }^{* *}$ University of Minho / Industrial Electronics Department, Guimarães, Portugal
}

\begin{abstract}
This paper will present and discuss the two major techniques used when inspecting an important parameter of the weft knitting industry: yarn input tension. The two techniques are frequency and time analysis. In this paper, the major features of each technique will be discussed and some examples will be presented.
\end{abstract}

\section{INTRODUCTION}

Due to their negative effect on productivity and quality, faults must be avoided at all cost, and with that purpose several measures are presently taken in knitting industry to minimize them. Nevertheless, faults are unavoidable because of the nature involved in the production of knitted fabric. In fact, the impact between the needles and cams, the forces and friction of yarn involved, and the ageing of the knitting elements contribute to the appearance of faults $[1,2,3,4,14]$.

With the objective of detecting faults, different surveillance systems are used, each one exploring a specific approach. One of them is by monitoring the knitting elements, in which mechanical devices and optical devices are used for detecting needle faults $[5,6]$. Another approach is the inspection of the knitted fabric as it is being produced. For that approach, vision and optical devices are used for detecting knitwear faults, which basically search for a pattern on the knitwear [7]. The third approach involves the monitoring of the yarn force, for which yarn detectors made from mechanical systems are usually used [8]. However, this last approach is less explored, and the systems used basically detect yarn break. The modern knitting machines started to replace those systems by optical sensors, because they do not touch in the yarn, situation that does not happen when the former yarn break detectors are used.

All the presented solutions are stand-alone devices and detect only a very specific set of faults. There are a set of information that can be provided to the technician and that these systems do not give.

Previous research showed that the Yarn Input Tension $Y I T$ - is indeed a valuable resource of information concerning in particular the knitting process, and in a more general term, the overall behavior of the knitting machine. YIT directly reflects the influence of the different mechanisms involved in the production of the knitted fabric $[9,11,12,14]$. With this approach one can detect the presence of a fault, and locate the origin. Moreover, it is

The authors wish to thank the sponsors of this research project, FCT Fundação para Ciência e Tecnologia, project POSI/SRI/39824/2001 and the University of Minho. possible to distinguish between faults' natures. Research was made using mathematical techniques such as clustering and discriminating analysis with success for evaluating the capability of fault identification [12,13]. The following sections will present a system that explores this approach and the techniques used, for possibly contribute for a better detection of faults.

\section{THE MEASUREMENT SYSTEM}

The measuring system is based on encoders, strain gauge force sensor, optical sensor, conditioning board and a PC, where the different applications run. The sensors are assembled in the knitting machine in a way that they do not require any special kind of structural modification.

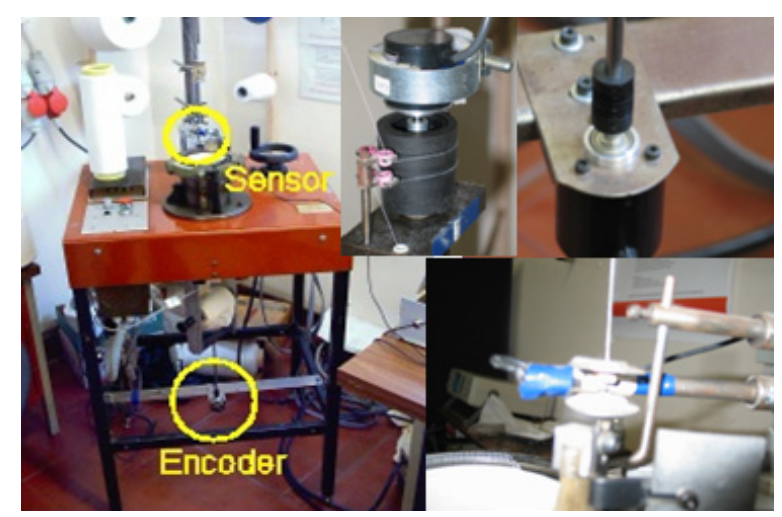

Figure 1. Assembled sensors on a sample knitting machine.

Note that the same system was also assembled on an industrial knitting machine. The knitting machines used for the experiments were: a sample making circular weft knitting machine with one positive feeding system, one cam, 168 needles and sinkers, 3.75" diameter cylinder, with speeds up to $200 \mathrm{rpm}$; and one industrial weft circular knitting machine with 36 positive feeding systems, 36 cams, 756 needles and sinkers, 12" cylinder diameter, and a top speed of $45 \mathrm{rpm}$.

The encoders are responsible of generating the signals necessary to calculate the yarn consuming rate, the rotation speed and synchronizing signals. The optical sensor is used to mark the spot where each revolution of the knitting cylinder starts. This sensor is used whenever the knitting cylinder vertical axis is inaccessible for assembling one of the encoders. The force sensor is placed nearby the knitting zone in order to measure the YIT, which is the base instrument for detecting the faults and malfunctions related with the knitting elements, yarn and systems directly involved with the knitting process. 
All sensors are connected to a data acquisition board by means of a conditioning board. The developed measuring system allows the measurement of several force ranges, from $0-5.0 \mathrm{cN}$ up to $0-200 \mathrm{cN}$. The adjustments of the force range and calibration are made through software. The system is able to measure YIT virtually at any speed for the present industrial weft knitting machines.

The YIT waveform and the remaining control signals are acquired through the conditioning board and passed into the data acquisition board. An application, KnitLAB, stores the information and is capable of acquiring, save to file, retrieve from file, analyze and manipulate the waveforms with different processing tools, like digital filtering, spectral analysis, correlations, etc.

The acquisition can be made by using time sampling or space sampling. Both approaches have their advantages and drawbacks. From the knitting process point of view, it seems very advantageous the use of space sampling. This is due to the problem of speed variability. From the experiments made up to the present date and for both the industrial and sample knitting machines, it was clear that the rotating speed of the knitting cylinder had a variability of about $0.5 \%$. This variability is random and, when using time based sampling, produced a rotation/cycle with an average length in points with a small variability in both ways. This problem would promote the need to recalculate the number of points per rotation/cycle in order to have a constant length, when one intended to compare complete waveforms. This would also produce slight differences for the exact location of a fault in case of happening, although the error is quite small, of about $0.49 \%$ for the sample knitting machine. Another problem is related with the speed at which the cylinder is rotating. The sampling rate would also need to be recalculated if the rotation speed was modified. Lastly, the digital filtering stage of the application would also need to be modified each time the rotation speed was changed and the reference frequency would always be an average measure.

On the other hand, by using space based sampling, all these problems would vanish. This is because the sampling of the signal would occur always at the same place, no matter how fast the machine was running. The number of points per rotation/cycle would always be the same, which could avoid all the calculations needed for length adjustments. The precision would be also optimized, since the points were acquired at the same places. Finally, it would be necessary to design the digital filtering stage only once, since the sampling rate reference would always be the same, independent from the machine's speed.

\section{YIT POWER SPECTRUM ANALYSIS}

One of the possibilities of the developed application is the representation of the YIT in frequency domain, through the spectrum analysis. This analysis can be performed both offline as well as online. Fig. 2 illustrates the main window of the application used to view the power spectrum in offline mode. The power spectrum is represented in a normalized frequency, where the sampling rate is equivalent to the number of points acquired during one entire rotation/cycle.

The application allows the representation of the power or amplitude spectrum for each rotation/cycle, or the average power and amplitude spectrum. The latter reduces the noise that could be present if only one rotation/cycle was considered.

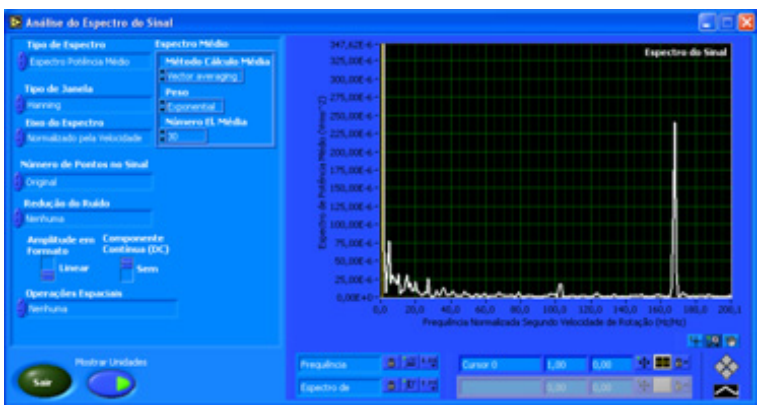

Figure 2. Frequency analysis main window for cotton yarn.

TABLE I. TYPICAL FREQUENCIES ON POWER SPECTRUM FOR SAMPLE KNITTING MACHINE.

\begin{tabular}{|c|c|}
\hline $\begin{array}{c}\text { Normalized } \\
\text { Frequency }(\mathrm{Hz})\end{array}$ & Physical Meaning \\
\hline 1 & One Rotation/Cycle \\
\hline $4-5$ & Feeding System \\
\hline $6-20$ & Faults and abnormalities \\
\hline 168 & Number of needles \\
\hline
\end{tabular}

Table 1 presents the most usual frequency and frequency ranges obtained when inspecting the averaged power spectrum of the YIT for the sample knitting machine. The most curious result is the frequency that coincides with the number of needles used in the knitting machine. This frequency can be obtained by using the following expression:

$$
f_{\text {needles }}=\left.\frac{n a}{60}(\mathrm{~Hz})\right|_{\substack{n=\text { cylinder speed }(\mathrm{rpm}) \\ a=\text { needles number in cylinder }}}
$$

Acquiring the signal with a time based sampling rate would produce $f_{\text {needles }}$ directly proportional to rotating speeds, as Table 2 shows. Using the space based sampling, the spectrum becomes normalized with the speed and thus it will not vary in frequency values. As a consequence, and for a given knitting machine with a needles, the frequency representing the resulting YIT needles harmonic will be always the same and equal to $a$. 
TABLE II. NEEDLES FREQUENCY FOR SPEEDS EXPERIMENTED ON THE SAMPLE KNITTING MACHINE.

\begin{tabular}{|c|c|c|}
\hline $\begin{array}{c}\text { Rotational } \\
\text { Speed }(\mathrm{rpm})\end{array}$ & $\begin{array}{c}\text { Linear } \\
\text { Speed }\left(\mathrm{ms}^{-1}\right)\end{array}$ & $\begin{array}{c}\text { Needles } \\
\text { Frequency }(\mathrm{Hz})\end{array}$ \\
\hline 35 & 0.17 & 98 \\
\hline 54 & 0.27 & 151 \\
\hline 73 & 0.36 & 204 \\
\hline 92 & 0.46 & 258 \\
\hline 110 & 0.55 & 308 \\
\hline 130 & 0.65 & 364 \\
\hline 148 & 0.74 & 414 \\
\hline
\end{tabular}

The same behavior applies to all remaining frequencies in the spectrum, allowing an easier interpretation concerning possible problems that may occur during production.

The spectrum analysis assumes a particular importance due to the nature of the circular knitting machines' mechanisms. In fact, almost all moving parts depend from one main engine and their movement is almost always circular. Any abnormality will thus produce some kind of periodic behavior, which can be more easily understood in frequency domain. One particular example is the eccentricity of the yarn feeding system. This system rotates in a directly proportional speed of the needles cylinder. Any sort of eccentricity will be reflected in the YIT. With the aid of spectrum analysis is possible to detect the problem.

The following figures represent the averaged power spectrum for normalized frequency in respect to needles cylinder speed (the knitting machine's actual speed), using a Hanning window and exponential weight when considering the average of each spectrum.

Fig. 4 and Fig. 5 show how this problem can be easily detected. The YIT waveform was obtained for $100 \%$ staple fiber (cotton yarn ) on a sample knitting machine at a speed of $148 \mathrm{rpm}$, which means $0.74 \mathrm{~ms}^{-1}$. Deliberately, a small piece of adhesive was placed on the yarn feeder cylinder in order to observe the effect in the YIT. It can be clearly seen that the harmonic at $4 \mathrm{~Hz}$ has increased. This particular harmonic is related with the yarn feeder. Note that this harmonic can be displaced between 3 and 5 or even $6 \mathrm{~Hz}$. The explanation for this effect is that the yarn feeding system is directly connected to a shaft bonded to the needles cylinder and with linear adjustment for speed rotation. This adjustment allows the modification of the tightness factor and loop length, which means adjustments for coarser or tighter knitwear. The result is the increase or decrease of the rotation speed for the yarn feeder, thus resulting in a shift of the harmonic in the vicinity of $4 \mathrm{~Hz}$. For this particular frequency, a tightness factor of 13 and a loop length of $0.36 \times 10^{-3} \mathrm{~m}$ are obtained. It is also worth to note that by using spectrum analysis one can estimate the consumption of the yarn for each needles' cylinder rotation without having to use a particular length measure sensor, like an encoder.

For the particular case of detecting faults, the spectrum analysis revealed that there exist a typical range of frequencies that are present when a fault occurs.

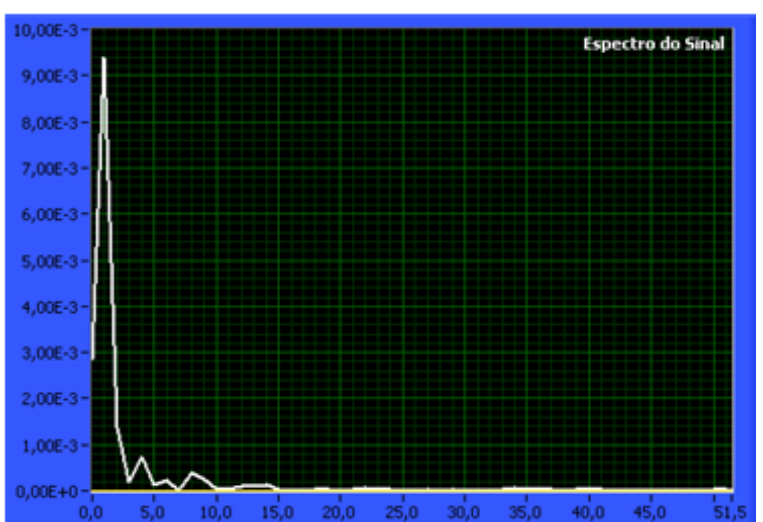

Figure 3. Average power spectrum for cotton yarn at $0.74 \mathrm{~ms}^{-1}$ linear speed $\left(\mathrm{V}_{\mathrm{rms}}^{2} \mathrm{x} \mathrm{Hz}\right)$. Cycles without problems.

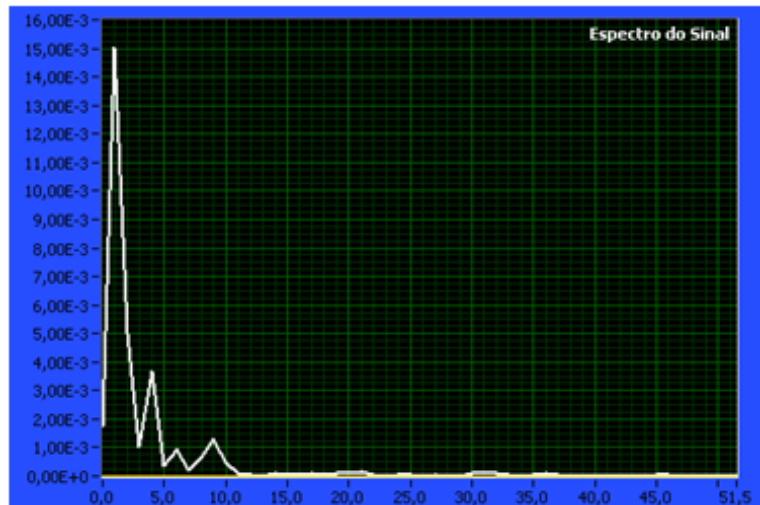

Figure 4. Average power spectrum for cotton yarn at $0.74 \mathrm{~ms}^{-1}$ linear speed $\left(\mathrm{V}_{\mathrm{rms}}^{2} \mathrm{x} \mathrm{Hz}\right)$. Eccentricity in the yarn feeder.

The results presented in Table 3 refer to experiments made for the same raw material (cotton), and for the speed of $0.74 \mathrm{~ms}^{-1}$. The spectral representation of a fault is generally located at low frequencies, between 3 and 20 Hz. The magnitudes are very low (generally less than -25 $\mathrm{dB}$ ), and although there are slight differences in the power spectrum for each case, the risk of misinterpreting the cause of the fault is generally considerable. Nevertheless, it is possible to distinguish a fault from a fault-free working condition.

TABLE III. FREQUENCIES FOR FAULTS.

\begin{tabular}{|c|c|c|c|c|c|}
\hline Frequency & $\begin{array}{c}\text { No } \\
\text { Fault }\end{array}$ & $\begin{array}{c}\text { Needle } \\
\text { Fault }\end{array}$ & $\begin{array}{c}\text { Broken } \\
\text { Hook }\end{array}$ & $\begin{array}{c}\text { Sinker } \\
\text { Fault }\end{array}$ & $\begin{array}{c}\text { Broken } \\
\text { Butt in } \\
\text { Sinker }\end{array}$ \\
\hline 1 & $\mathrm{X}$ & $\mathrm{X}$ & $\mathrm{X}$ & $\mathrm{X}$ & $\mathrm{X}$ \\
\hline 3 & & $\mathrm{X}$ & & $\mathrm{X}$ & $\mathrm{X}$ \\
\hline 4 & $\mathrm{X}$ & & $\mathrm{X}$ & & \\
\hline 6 & & $\mathrm{X}$ & $\mathrm{X}$ & $\mathrm{X}$ & $\mathrm{X}$ \\
\hline $8-9$ & $\mathrm{X}$ & & $\mathrm{X}$ & & $\mathrm{X}$ \\
\hline $10-12$ & & $\mathrm{X}$ & & $\mathrm{X}$ & \\
\hline 14 & & & $\mathrm{X}$ & & $\mathrm{X}$ \\
\hline$\ldots$ & & & & & \\
\hline 168 & $\mathrm{X}$ & $\mathrm{X}$ & $\mathrm{X}$ & $\mathrm{X}$ & $\mathrm{X}$
\end{tabular}

In conclusion, the spectrum analysis allows the identification of some particular problems, namely those with periodic behavior, such as eccentricities. It can also give an idea of the consumption of yarn per rotation. However, its direct inspection does not allow a clear 
distinction between different causes of faults. The location of the fault, in particular for knitting elements faults, is also not possible. The use of wavelets can be an alternative, due to their capability to represent both in time and frequency domain. Some preliminary experiments showed however that no significant improvements where found by using wavelets.

Since there still exist abnormalities that can be detected by inspecting the power spectrum of the YIT, a procedure running in real time was proposed in order to diagnose and detect the problems during the knitting process.

Fig. 6 illustrates such procedure. It is a particular part of a larger one that also runs in real time in an application called MonitorKnit, which is responsible to detect and locate the faults and abnormalities during production. The results of the different modules are combined on a higher order decision module that will decide if the detected problem is a critical one, thus requiring the stop of the machine, or is a problem that although present, does not produce a fault in the knitted fabric.

The acquired signal is transformed through FFT into frequency domain and typical harmonic components are extracted from the spectrum. The result is compared with a YIT previously acquired and transformed signal, obtained from a YIT fault-free functioning of the knitting machine. The signal represents one rotation/cycle of the YIT. The result of this comparison is then provided into the decision module that will produce a result and this result is in its turn fed into a higher order decision module that will decide if the knitting machine should stop. This means that the decision module will determine if this is a critical problem. The lower level decision module on Fig. 6 decides the presence of eccentricities and also tries to identify is the current rotation/cycle has or has not a fault. This is returned as one single value.

\section{YIT TIME ANALYSIS}

The analysis of the YIT in time domain allows the detection of several and problems related with the production of knitted fabric. As Fig. 7 and frequency analysis shows, the YIT is basically a waveform with a main harmonic that coincides with the formation of loops on one course. So, it would resemble a sinusoidal waveform mainly for the cases where cams are non-linear. However, this case is not always observed, because there are all the other mechanics involved in the production of the knitted structure that will induce other harmonics, and thus changes on the shape of the YIT waveform.

Since the YIT is directly related with what happens inside the knitting zone, any sort of disturbance will be reflected in this waveform. The disturbances can be eccentricities, faults, yarn breaks, etc. All these will produce variability in the YIT.

Fig. 8 shows the same fault (one broken hook) produced in different needles' cylinder positions. The working speed is $0.74 \mathrm{~ms}^{-1}$, well inside the industrial knitting speeds. As it can be seen, there is a sudden variation in the YIT produced by the defective knitting element. Typical behaviors happen for all other problems and can be observed in the waveform, in spite of not being possible to detect by eye inspection during production.

As it can be confirmed in Fig. 8, the problem can be easily identified from the normal functioning of the knitting machine and the location of the fault can be

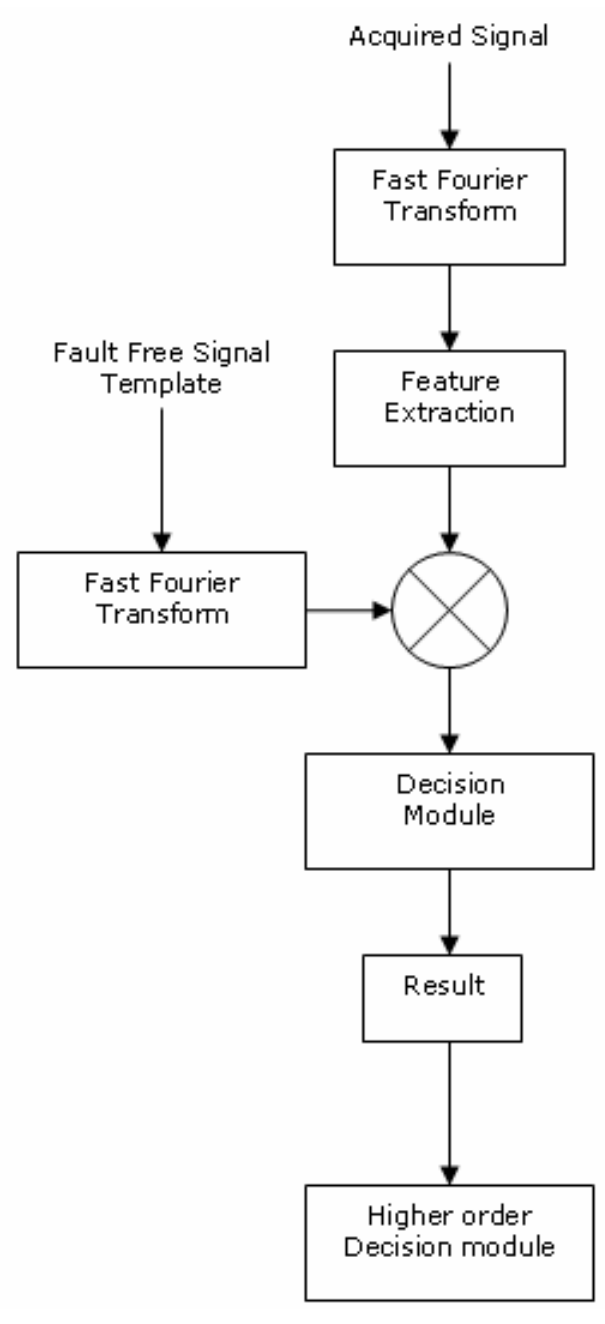

Figure 5. Frequency analysis module.

determined with excellent accuracy (one needle) and precision. This constitutes an important advantage from the production point of view, since there is no need to change more than one needle, with evident economic benefits.

In order to automatically detect this kind of fault some

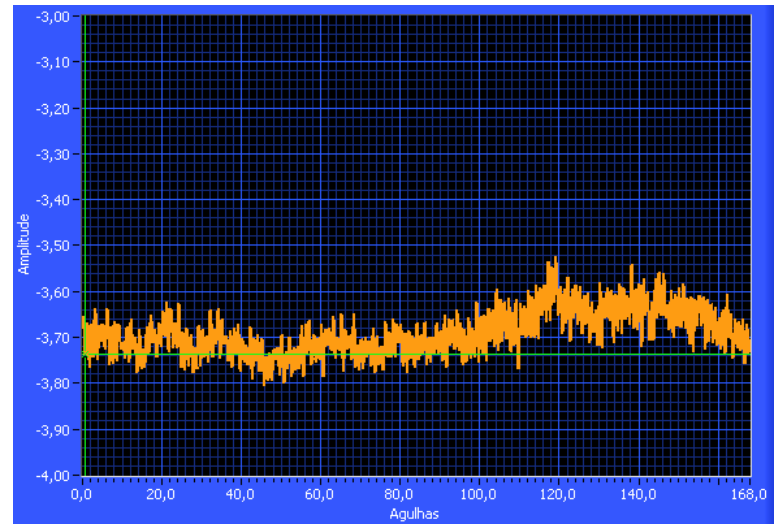

Figure 6. One rotation/cycle YIT time domain waveform for sample knitting machine (V x needle position). The yarn used was $100 \%$ cotton, 21 tex, for a speed of $0.36 \mathrm{~ms}^{-1}$.

techniques were implemented. One of them involves the use of $A M C D$ (Average Magnitude Cross Difference) 


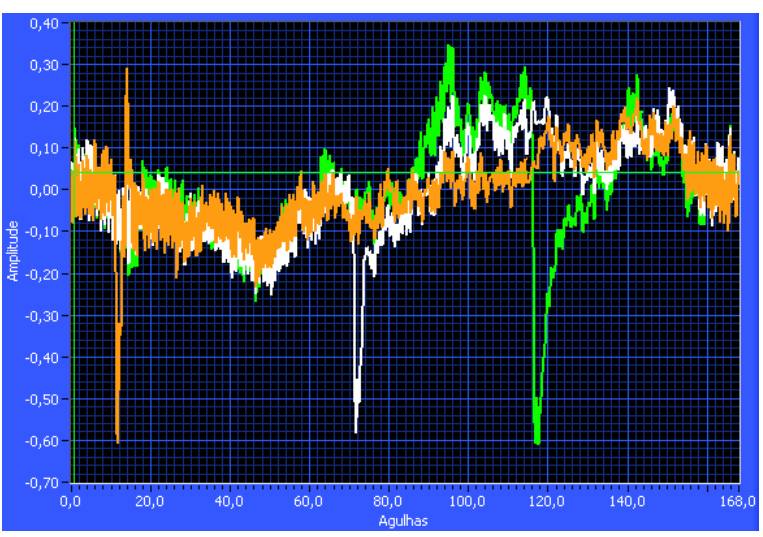

Figure 7. Fault occurring in different locations (different needles). The yarn is the same and the fault is one broken hook.

$[16,17]$, in which a template traverses the waveform as it is being acquired, thus producing a new waveform. When the signal is different from the usual, i.e., a fault or an abnormality is present the measure will return a higher value, thus modifying the resulting waveform.

Fig. 11 and Fig. 12 present the $A M C D$ applied to the YIT waveform. As it can be seen from Fig. 9, there is a significant variability on YIT from one rotation/cycle to the next, which makes difficult to use YIT directly for detecting faults. The use of synchronization (Fig. 10) allows the vanishing of variability; however it hides problems that can happen only once. $A M C D$ has the capability of standing out the fault even if it occurs only once. The example shown in Fig. 12 illustrates exactly one situation where it happened. Moreover, the $A M C D$ resulting waveform is smoother than YIT waveform, which allows to an easier identification of one fault. The accuracy of the location of the fault is somewhat sacrificed, but since the delay in known, one can estimate the position where the fault occurred with the same accuracy as if was used the real YIT.

\section{FURTHER DEVELOPMENTS}

The frequency analysis needs to be further developed, in order to improve the decision module illustrated in Fig. 4. Other approaches involving different techniques for frequency analysis are also under research.

The approach using $A M C D$ proved to be very efficient. Further development, namely experiments with a significant number of raw material, knitted structures and knitting machines will be made in order to confirm the efficiency of this approach. However, other approach, involving less processing effort is under research.

Since the faults show different shapes, there exists a strong possibility to automatically distinguish the faults. With that objective in mind, a pattern recognition system is being developed.

At the same time a more cost effective measuring device is under refinement, which will allow the implementation of this technology on each yarn used on the knitting machine for an affordable price.

Finally, other branch of the project involves the development of a yarn feeder with the purpose of reducing the variability of the YIT. This actuator will be another part of the entire system.

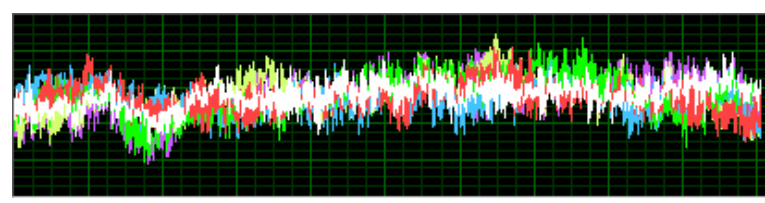

Figure 8. Ten YIT waveforms superimposed.

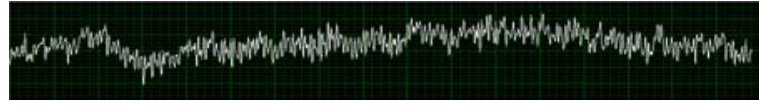

Figure 9. YIT space synchronised waveform.

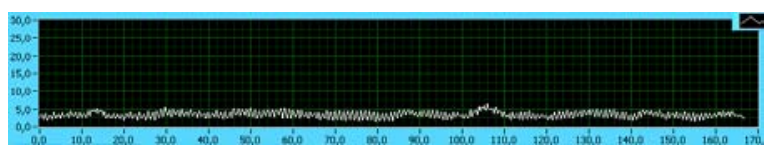

Figure 10. AMCD applied to YIT. No fault present.

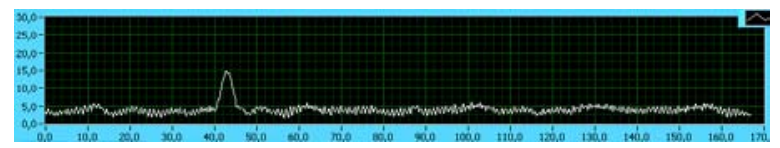

Figure 11. AMCD applied to YIT. One broken hook present.

\section{CONCLUSIONS}

The YIT is an important parameter for weft knitting industry and its inspection allows the detection of several problems during production. This paper presented the two major techniques considered in this research for inspecting the YIT waveform - Frequency and Time analysis. The typical problems that each one of the techniques reveal from YIT were presented and discussed as well as their advantages and complementarities. Finally, some examples of their application were presented.

\section{REFERENCES}

[1] G. Buhler, L. Pestel, H. Hait, "Requirements in regard to future circular knitting assurance systems- Practical trial with a futureoriented monitoring system", Melliand textilberichte, 1, 1994, pp $39-42$.

[2] T Push, I. Wunsh, R. Seifert, P. Offermann, "Fine structure of yarn tension on large-diameter circular knitting machines", Melliand textilberichte 1-2, 1997, p 52-55.

[3] H. Behr, "Accessories for circular and flat knitting machines", Knitting Technology, 1996, Vol. 18, 4, p. 184-189.

[4] J. Bauer, "Positive yarn feed on knitting machines", Knitting Technology, 1996, Vol 18, 4, p. 190-193.

[5] Needle Detector NW from Memminger-IRO , reference 335.905.001.07 DSNL/5, official website http://www.memmingeriro.de/.

[6] Digital Needle Sensor Type 4020, Protechna, official website http://www.protechna.de/e/nadtast_dd.htm.

[7] Fabric Scanner LMW 3, Memminger-IRO, reference 040.905.000.01 DUDD/40, official website http://www.memminger-iro.de/.

[8] Yarn detectors OFW/UFW, Memminger-IRO, official website http://www.memminger-iro.de/

[9] A. P. Catarino, A.M. Rocha, J. L. Monteiro, "Monitoring Systems for fault detection on circular knitting machines through yarn input tension", in Proceedings of the ICOM 2003 - International Conference on Mechatronics, ISBN 186058420 9, pg 465-470.

[10] André Catarino, Ana Rocha, João Monteiro, "Low Cost Sensor for the Measurement of Yarn Input Tension on Knitting Machines", in proceedings of the ISIE 2003 - International Symposium on Industrial Electronics, ISBN 0-7803-7912-8. 
[11] André Catarino, Ana Rocha, João Monteiro, "Monitoring Knitting Process through Yarn Input Tension: New Developments", in proceedings of IECON 2002, ISBN 0-7803-7475-4.

[12] A. Catarino, A. M. Rocha, J. Monteiro; "Automatic Fault Identification in Knitting Machines", in Proceedings of Signal Processing, Pattern Recognition and Applications 2001 IASTED International Conference, pp.5-10.

[13] M. Araújo, A. Rocha, H. Hong, A. Catarino, "Towards the Automatic Control of Sewing and Knitting Operations", in Proceedings of World Automation Congress 2000, pp. 636-641.
[14] A. Catarino, Dinâmica da Tricotagem: Estudo da Dinâmica da Tensão de Entrada do Fio e sua Aplicação em Controlo de Qualidade, Msc Thesis, University of Minho, 1998.

[15] David J. Spencer, Knitting Technology, 2nd Ed., Pergamon Press: 1989.

[16] E. C. Ifeachor and B W. Jervis, Digital Signal Processing a practical approach, 2nd edition, Prentice Hall, Harlow, 2002, pg 877-887.

[17] B.U. Kohler, C. Hennig, R. Orglmeister, "The Principles of Software QRS Detection", IEEE Engineering in Medicine and Biology, January/February, 2002, pg 42-57. 